\title{
Construcción de paz en Colombia a partir del cumplimiento de la responsabilidad legal y social de las empresas
}

Peace Construction in Colombia based on Compliance with Companies' Legal and Social Responsibilities

Autor: Jorge Antonio Cortés Torres

DOI: https://doi.org/10.25058/1794600X.1927 


\title{
CONSTRUCCIÓN DE PAZ EN COLOMBIA A PARTIR DEL CUMPLIMIENTO DE LA RESPONSABILIDAD LEGAL Y SOCIAL DE LAS EMPRESAS*
}

\author{
Peace Construction in Colombia based on Compliance with \\ Companies' Legal and Social Responsibilities \\ A construção da paz na Colômbia com base no cumprimento da \\ responsabilidade legal e social das empresas
}

Jorge Antonio Cortés Torres ${ }^{a}$ jantoniocortes@unicolmayor.edu.co

Fecha de recepción: 12 de abril de 2020 Fecha de revisión: 31 de agosto de 2020 Fecha de aceptación: 02 de diciembre de 2020

\section{RESUMEN}

En concordancia con lo señalado por el artículo 333 de la Constitución Política de Colombia, la actividad económica y la iniciativa privada son libres dentro de los límites del bien común. La empresa como base del desarrollo tiene una función social que implica obligaciones. Con base en lo anterior, es preciso comprender cuál es la proyección y el límite de la libertad empresarial al igual que la función social que la ha de caracterizar. Este límite debe partir del concepto de Estado Social de Derecho, que de acuerdo con la referida Constitución Política caracteriza a Colombia, y en virtud del cual, todas las personas deben vivir sometidas al imperio de la ley tomando como constante que nuestro derecho termina en donde empieza el de los demás. En este orden de ideas, es necesario abordar el tema de la regulación legal y social de la empresa con el fin de determinar cuáles son las reglas que regulan las relaciones sociales dentro de ésta y, cuáles son las obligaciones legales que adquiere el empresario, lo que también busca brindarle una seguridad jurídica como inversionista. En este sentido, la responsabilidad social en el ámbito empresarial o corporativo es entendida como

\footnotetext{
* Artículo sobre avances de investigación en torno al proyecto de investigación: Diversidad cultural para la construcción de paz: Posibilidades desde las Prácticas de Responsabilidad Social Organizacional. Fase 2. Aprobado por la Universidad Colegio Mayor de Cundinamarca.

a. Docente de planta en Universidad Colegio Mayor de Cundinamarca. Facultad de Ciencias Sociales. Programas de: Trabajo Social y, Especialización en Gerencia en Seguridad y Salud en el Trabajo.
} 
el compromiso que las organizaciones públicas y privadas asumen con relación a la sociedad, que además debe estar reflejado en inversión social con las comunidades y con el entorno.

\section{PALABRAS CLAVES}

Responsabilidad; derechos; deberes; empresa; comunidades; individuos; bienestar; paz.

\section{ABSTRACT}

In accordance with Article 333 of the Political Constitution of Colombia, there is freedom concerning the economic activity and the private initiative, within the limits of the common good. Companies, as the basis for development, have a social function that implies certain obligations. Therefore, it is important to understand what is the projection and limit of businesses' freedom as well as their social function. This limit must be drawn from the concept of the Social State of Law, which according to the Political Constitution characterizes Colombia and by which all people must live subjected to the law, taking into consideration that our rights end where the rights of the community begin. Accordingly, we need to address the issue of legal and social regulations of companies, with the purpose to determine which are the rules that regulate the social relations within, and what are the legal obligations that an entrepreneur acquires, which also intends to provide businessmen legal certainty as investors. In this sense, social responsibility in the business or corporate sphere is understood as the commitment that public and private organizations assume in relation to society, which must also be reflected in social investment with the communities and the environment.

\section{KEY WORDS}

Responsibility, rights, duties, company, communities, individuals, welfare, peace.

\section{RESUMO}

De acordo com o disposto no artigo 333 da Constituição Política da Colômbia, a atividade econômica e a iniciativa privada são livres dentro dos limites do bem comum. A empresa como base do desenvolvimento tem uma função social que implica obrigações. Com base no exposto, é necessário compreender qual é a projeção e o limite da liberdade empresarial, bem como a função social que deve caracterizá-la. Este limite deve partir do conceito de Estado Social de Direito, que segundo a citada Constituição Política caracteriza a Colômbia, e em virtude do qual todas as pessoas devem viver sujeitas ao Estado de Direito, tendo como constante que nosso direito termina onde os outros começam. Neste sentido, é necessário abordar a questão da regulação jurídica e social da empresa de forma a determinar quais são as regras que regulam as relações sociais no seu seio e quais são as obrigações legais que o empregador adquire, quais são as que também procura para fornecer segurança jurídica como um investidor. Nesse sentido, a responsabilidade social na esfera empresarial ou empresarial é entendida como o compromisso que as organizações públicas e privadas assumem em relação à sociedade, que deve se refletir também no investimento social com as comunidades e o meio ambiente..

\section{PALAVRAS-CHAVE}

Responsabilidade; Direitos; trabalho de casa; o negócio; comunidades; indivíduos; bem estar; Paz.

\section{INTRODUCCIÓN}

La responsabilidad legal es aquella establecida por norma legal y que tiene que ver con el cumplimento de una función social. En este sentido, la responsabilidad social es el compromiso y el deber que asumen los individuos como miembros de una sociedad o empresa de contribuir en la construcción de una sociedad más justa, incluyente y equitativa. A partir de lo anterior, es necesario preguntarse si las empresas en Colombia cumplen o no con su responsabilidad legal y social. Para responder el interrogante, es necesario precisar que la responsabilidad social y legal empresarial no debe centrarse tan solo en el discurso, en una buena intención o una simple estrategia de mercadeo. Por el contrario, debe enfocarse en realizar una verdadera inversión social que se proyecte en un aporte para el desarrollo y contribuya al mejoramiento de la calidad de vida de las personas, tanto en el entorno laboral como en los entornos comunitarios. Dentro de este propósito es necesario además, tener en cuenta la información sobre cuál es la percepción de los individuos en materia de responsabilidad social 
empresarial, al tiempo que se precisen algunos estudios que reflejan cuál ha sido la dimensión del propósito empresarial en casos específicos.

Cabe resaltar que las responsabilidades social y legal empresarial son aspectos que han venido señalándose de manera reiterativa por parte de las organizaciones. Es por ello que resulta necesario establecer si se refleja o no en una real vivencia por parte de sus principales gestores, en este caso las empresas. De acuerdo con lo anterior, es pertinente llevar a cabo un estudio sobre la responsabilidad social y legal de las empresas a partir de la visión de diferentes actores sociales que indiquen cuál es la percepción frente a su aplicación.

El abordaje del tema debe partir inicialmente del interrogante sobre cuál es el compromiso social y legal que debe asumir la empresa hacia la sociedad y su contribución al mejoramiento de la calidad de vida de las personas y las comunidades a partir de la aplicación de estos conceptos sociales y legales. Esto con el objeto de establecer cuál es su aporte en la solución de los problemas sociales del país, causados en su mayoría por la exclusión social y la inequitativa distribución de la riqueza que lo ha caracterizado como sociedad. En el aspecto referente a la contribución de la empresa al mejoramiento de la calidad de vida, la Corte Constitucional mediante la Sentencia C-189 de 2006, en la parte pertinente señaló:

En este orden de ideas, la propiedad privada ha sido reconocida por esta Corporación como un derecho subjetivo al que le son inherentes unas funciones sociales y ecológicas, dirigidas a asegurar el cumplimiento de varios deberes constitucionales, entre los cuales, se destacan la protección del medio ambiente, la salvaguarda de los derechos ajenos y la promoción de la justicia, la equidad y el interés general como manifestaciones fundamentales del Estado Social de Derecho (C.P. arts. $1^{\circ}$ y 95 , nums., 1 y 8) (Sala Plena, C-189, 2006).

Asimismo, el abordaje del tema debe partir del concepto constitucional de Estado Social de Derecho, como país democrático, participativo y pluralista, fundado en el respeto de la dignidad humana en el trabajo y la solidaridad de las personas que la integran al igual que en la prevalencia del interés general. El mismo ordenamiento jurídico fija como fines del Estado servir a la comunidad, promover la prosperidad general y garantizar la efectividad de los principios, derechos y deberes consagrados en la Constitución; facilitar la participación de todos en las decisiones que los afectan, asegurar la convivencia pacífica y la vigencia de un orden justo. En este orden de ideas el documento revisa los conceptos sobre responsabilidad legal $y$ social, continua con el análisis de su aplicación en Colombia y finaliza con una reflexión sobre cómo debe ser su implementación y aplicación como forma de construcción del tejido social y que contribuya a la consolidación de la paz en el país.

\section{METODOLOGÍA}

Este documento, así como la investigación que lo precede responden a las lógicas propias de un ámbito particular: la sociología de la cultura, en la postura de R. Williams. Esta sociología, se nutre de diferentes posturas y enfoques epistemológicos o paradigmáticos, así como de herramientas metodológicas.

El análisis sobre las prácticas de responsabilidad social $\mathrm{y}$ legal organizacional interpretadas a la luz de sus aportes al fomento del respeto y defensa de la diversidad cultural y la construcción de paz, responde esencialmente a la postura epistemológica o paradigma hermenéutico, en particular, al análisis cultural hermenéutico (propio de la sociología de la cultura y de las ciencias humanas y sociales en general).

Quiere ello decir que esta propuesta debe ser interpretada como un acercamiento a una pretensión más amplia en la que desde el análisis cultural hermenéutico, se busque promover procesos sociales para la construcción de tejido social, identidad, equidad, inclusión y defensa de la diversidad a través del diálogo social, con el propósito de generar prácticas específicas y reales de responsabilidad social y legal organizacional que contribuyan a consolidar escenarios de paz.

\section{RESULTADOS}

Como se señaló de manera antecedente, el abordaje del tema partió del interrogante sobre cuál es el compromiso social y legal que debe asumir la empresa hacia la sociedad, y su contribución al mejoramiento de la calidad de vida de las personas y las comunidades. A efecto, fueron identificadas algunas prácticas de responsabilidad social de algunas empresas 
para luego pasar analizar su real cumplimiento y aplicación en los entornos sociales.

Con el ánimo de contar con elementos de juicio suficientes para determinar el grado de conocimiento de la población en torno a las prácticas de responsabilidad social empresarial, se diseñaron formularios de entrevista para ser aplicados al azar a diferentes grupos poblacionales, como potenciales beneficiarios de dichas prácticas, tales como jóvenes, mujeres rurales, afrocolombianos, adultos mayores $y$ personas en situación de discapacidad, en los municipios de Tocancipá, Zipaquirá, Ubaté, Sopo, Ubaque y Bogotá, entre otros. Las categorías de las preguntas y los resultados aplicados a 35 personas, pertenecientes a grupos poblacionales especialmente vulnerables, arrojaron los siguientes resultados en los aspectos más relevantes:

En el cuestionario de entrevista fue incluido un aspecto relacionado con la presencia de víctimas del conflicto armado, al considerar que debe ser un grupo poblacional prioritario en materia de responsabilidad social. Respecto al interrogante relativo al conocimiento de la presencia de víctimas del conflicto armado, los 35 entrevistados contestaron: Si hay víctimas: 16 , No hay víctimas: 12 , No sabe: 3 , No informa: 4 .

Quienes respondieron afirmativamente conocer de la presencia de víctimas del conflicto, se refieren en particular a personas que han sido desplazadas. Dentro de las poblaciones que manifestaron reconocer se encuentran jóvenes y niños que han sido desplazados de sus lugares de origen por motivo del conflicto armado, y personas que habitan en zonas rurales, fincas y zonas donde ha ocurrido conflicto, como el caso de Risaralda.

Asimismo, en el cuestionario fue incluido el interrogante relativo al conocimiento de sobre el desarrollo de prácticas de RSE que contribuyen en la construcción de paz; y en este sentido, el grupo poblacional entrevistado contestó: No las conoce: 29, Si las conoce: 5, No informa: 1. De los cinco entrevistados que han mencionado conocer las prácticas, refieren más a acciones del gobierno, a través de distintos programas ofrecidos en forma de subsidios.
También fue incluido un interrogante relativo al conocimiento sobre Acuerdos de Paz; al respecto el grupo entrevistado contestó: No los conoce: 21, Si los conoce: 12, No informa: 2. De los 12 que han manifestado conocer los Acuerdos de Paz, han mencionado haberlos conocido o escuchado en programas de televisión o por su participación en talleres organizados por una ONG.

A partir del ejercicio sobre la percepción de los diferentes grupos poblacionales como eventuales destinatarios de las prácticas de responsabilidad social, se buscó establecer el nivel de percepción sobre las prácticas de responsabilidad social $\mathrm{y}$, desde las respuestas se propone, primero que todo, la puesta en práctica de estrategias para la masificación de la información sobre ellas, para lograr un mayor conocimiento, introyección y aplicación real de tales prácticas, de tal manera que los individuos y las comunidades puedan ser destinatarios no tan solo potenciales, sino reales, de las acciones en tal sentido. Adicionalmente, se propone que los mismos destinatarios de estas prácticas asuman una responsabilidad social en la construcción de tejido social, a través de los mecanismos de participación social que se relacionan directamente con estas prácticas. A partir de dichos instrumentos, su análisis e interpretación, junto con los demás elementos de juicio que formaron parte del proyecto de investigación institucional, se sugieren nuevos aportes para la construcción de paz a partir de la responsabilidad social empresarial.

Dentro de la investigación sobre la ambientación y la cimentación de una cultura para la paz a nivel nacional y regional, se encuentran algunos ejemplos de prácticas de construcción de paz en Colombia, en las que han participado actores sociales empresariales a nivel regional. Dentro de ellas podemos citar, entre otras, las referidas en el documento de la Cámara de Comercio de Bogotá (Fundación Ideas para la Paz e Instituto Catalán Internacional para la Paz, 2015). En el estudio se afirma que:

Dentro del conjunto de intervenciones que contribuyen a la paz en lo local también se destacan: la Ciudadela Educativa en Barrancabermeja, los Centros de Reconciliación en Bugalagrande, y el fomento ganadero en la Macarena. Estas tres iniciativas que documentó la FIP dan cuenta 
de apuestas empresariales que contribuyen al fortalecimiento del tejido social de comunidades que han estado atravesadas por el conflicto y al mejoramiento de sus condiciones de vida y de manera más amplia de las condiciones locales (p. 53).

La Ciudadela Educativa en Barrancabermeja es una iniciativa de la empresa Merieléctrica que en la década de los 90 fue encargada de la construcción de una planta eléctrica en la comuna 7 de esta ciudad. Esta empresa con apoyo de Tipiel inició un ejercicio de diálogo y construcción de confianza con los habitantes de dicha comuna. Esto permitió identificar vulnerabilidades del entorno y riesgos e impactos de la construcción. Al mismo tiempo este ejercicio creo las bases para el desarrollo del proyecto ciudadela educativa (p. 54).

Los Centros de Reconciliación, iniciativa con participación de Nestlé, tienen como objetivo ayudar al mejoramiento en las relaciones de los diferentes actores que se encuentran en el territorio. Estos centros evidencian cómo tras evaluar la manera cómo se relacionan con sus grupos de interés, una empresa decide invertir en el mejoramiento de tales relaciones. Así mismo, evidencia la reflexión que la empresa hace sobre su papel en los entornos (p. 54).

El proyecto MACA, iniciativa de La Alquería, se desarrolla en La Macarena y tiene como objetivo la generación de alternativas económicas para pobladores de 14 municipios del Meta, 5 de ellos pertenecientes a la zona de consolidación de La Macarena (p. 54).

Las iniciativas empresariales con enfoque de intervención territorial cuentan con una perspectiva de construcción de paz como proceso, y no como una acción puntual y acotada en el tiempo (p. 55).

Retomado el concepto de corresponsabilidad social para la construcción de paz es necesario precisar que la igualdad debe ser la constante, en el sentido de que todos debemos estar sometidos al imperio de la ley, lo que involucra tanto a los administrados como a las autoridades. De hecho las autoridades institucionales especialmente involucradas en la consolidación de la paz han señalado que:
Por su mandato constitucional, prevalece en la Policía el principio de igualdad de todas las personas en razón de sus derechos y obligaciones ciudadanas, pero en su acción pública orientada a la construcción de la paz, se privilegia el tratamiento diferencial de acuerdo a las identidades de cada grupo, reconociéndolas y respetándolas (Unidad Policial para la Edificación de la Paz, 2017, p. 48).

En este mismo sentido, el referido documento de la Policía Nacional de Colombia ha sostenido que:

Desde una perspectiva de construcción de paz, el mutuo entendimiento y el respeto por las diferentes comprensiones del conflicto son fundamentales para proveer de equidad, igualdad y justicia el abordaje pacífico de las diferencias. Construir paz requiere ajustar las acciones públicas a las diferentes identidades sociales respecto de las características particulares de los grupos y los individuos en razón de su edad, género, orientación sexual y situación de discapacidad (Unidad Policial para la Edificación de la Paz, 2017, p. 47).

Asimismo, en lo que respecta al diseño e implementación de variadas prácticas de responsabilidad social organizacional, en lo posible deben ser incorporadas dentro de un sistema de gestión corporativo para que a partir de un ciclo PHVA (planear, hacer, verificar y actuar), le permita desarrollar acciones que redunden en un beneficio social. En este mismo sentido, el sistema de gestión de responsabilidad social, deseablemente debe estar articulado con los otros sistemas de gestión como el de calidad, el laboral, el de seguridad y salud en el trabajo, el de prevención y atención a riesgos de desastres, el de salud pública, el de seguridad vial, entre otros, por cuanto si bien cada uno de los sistemas de gestión esta caracterizado por una especificidad; sin embargo, su armonización y articulación contribuirá a imprimirle a la organización la coherencia e identidad necesarias para el beneficio del medioambiente, los empleados, los clientes, la comunidad en general y para ella misma con el fin de garantizar su rentabilidad económica y social.

Lo anterior, por cuanto el concepto de responsabilidad social organizacional cada vez 
más está presente en el desarrollo del objeto social de las entidades y su dinámica productiva a partir de la misión, la visión y los objetivos organizacionales que deseablemente deben incorporar de manera progresiva los valores y principios característicos del proceder de cualquier actor social, incluyendo los aspectos morales, éticos, de calidad y de solidaridad, entre otros, los cuales deben ser recogidos dentro de la RSO y se relacionan, por ejemplo, con las acciones sociales, hacia el medio ambiente y los trabajadores, que generen como valor agregado un aporte para el desarrollo del país en los diferentes aspectos.

\section{DESARROLLO DEL TRABAJO}

Para el desarrollo del proceso de investigación que da lugar a este artículo, tanto en la primera como en la segunda fase, fueron identificadas las diferentes formas de responsabilidad social anunciadas por algunas empresas en el país, las cuales fueron analizadas junto con la tabulación de los formularios de entrevista que fueron aplicados a diferentes grupos de personas destinatarias de estas prácticas; y a partir de las respuestas, se observa: en primer lugar, en el país hace falta una mayor difusión de la información hacia comunidades o grupos poblacionales sobre diferentes temas, dentro de ellos las prácticas de responsabilidad social organizacional. Es innegable que dicha difusión debe ser canalizada a través de diferentes metodologías y no circunscritas tan solo a una de ellas como lo es la virtualidad. Lo anterior, por cuanto especialmente en las áreas rurales, las personas no tienen acceso a la conectividad o esta es deficiente.

Es por ello que, en la gran mayoría de respuestas, los entrevistados que han señalado conocer las prácticas de RSO, se refieren más a acciones del gobierno a través de distintos programas ofrecidos en forma de subsidios. Adicionalmente, en su mayoría los entrevistados han señalado conocer víctimas del conflicto armado en la comunidad a la cual pertenecen, pero al mismo tiempo desconocer el desarrollo de prácticas de RSO que puedan llegar a contribuir positivamente en la construcción de paz. Por lo tanto, en primer lugar, es necesario contar con más canales de difusión y más pedagogía hacia las comunidades para difundir amplia y objetivamente los acuerdos de paz que incluyen a los diferentes actores sociales $y$, dentro de ellos a las organizaciones empresariales y su correlativa responsabilidad social. Con el propósito de brindar una mayor información a las personas y a las comunidades es necesario el diseño y desarrollo de estrategias que se traduzcan en acciones de inversión social de manera mancomunada entre las instituciones y las organizaciones empresariales, por ejemplo, en materia de conectividad y alfabetización.

Para abordar el tema de la manera más objetiva posible es necesario recordar que las responsabilidades legal y social que caracterizan la función social de la empresa parten del concepto de Estado Social de Derecho, tal y como lo señala la parte pertinente del artículo $1^{\circ}$ de la Constitución Política (2020), el cual agrega además, que el país es participativo y pluralista, fundado en el respeto de la dignidad humana, en el trabajo y la solidaridad de las personas que la integran y en la prevalencia del interés general. Estos aspectos guardan estrecha consonancia con el artículo $2^{\circ}$ de la Constitución Política (2020) cuando señala que son fines esenciales del Estado: servir a la comunidad, promover la prosperidad general y garantizar la efectividad de los principios, derechos y deberes consagrados en la Constitución; facilitar la participación de todos en las decisiones que los afectan y en la vida económica, política, administrativa y cultural de la Nación y asegurar la convivencia pacífica y la vigencia de un orden justo.

Es importante recordar que la paz, así como todos los temas sociales, económicos, políticos, entre otros, está regulada por la ley dado que Colombia es un país regulado holísticamente a través de leyes, cuyo cumplimiento y observancia es obligatorio para absolutamente todos sus habitantes. Al mismo tiempo la Constitución Política (2020) señala que son fines esenciales del Estado, entre otros, asegurar la convivencia pacífica y la vigencia de un orden justo. Lo anterior es complementado por el artículo 22 que a la letra señala: "La paz es un derecho y un deber de obligatorio cumplimiento". Es de aclarar que desde el preámbulo de la Constitución Política se señaló que la misma era expedida en ejercicio de un poder soberano con el fin de asegurar a los integrantes la vida, la convivencia, el trabajo, la justicia, la igualdad, el conocimiento, la libertad y la paz.

Como se sabe, la Constitución Política es la norma de normas, es decir, la más importante en 
el país y el referente a partir de la cual deben ser expedidas las diferentes normas legales de otra e inferior categoría, que deberán someterse a la primacía de la Constitución. En este sentido es oportuno precisar que la prioridad en Colombia como se deduce de la propia Constitución Política es el respeto a la dignidad humana, su promoción y prosperidad como eje central de la sociedad.

En esa misma dirección, la parte pertinente del citado artículo 333 de la Constitución Política de Colombia (2020), la actividad económica y la iniciativa privada son libres dentro de los límites del bien común. La empresa, como base del desarrollo tiene una función social que implica obligaciones. En este sentido, el concepto de responsabilidad social organizacional implica que la empresa asuma una postura consecuente y comprometida con los impactos económicos, sociales y ecológicos que puedan generarse dentro del desarrollo de las actividades propias de su objeto social. En consonancia con lo anterior, también deben existir canales a través de los cuales se difundan masivamente tales acciones a los actores individual y colectivamente considerados, quienes son los principales destinatarios de las acciones propias de las responsabilidades legal y social corporativas.

En esta dirección, el Código de Comercio (2020), señala que la empresa en Colombia está definida como toda actividad económica organizada para la producción, transformación, circulación, administración o custodia de bienes, o para la prestación de servicios. Dicha actividad se realizará a través de uno o más establecimientos de comercio. Por otro lado, el artículo 194 del Código Sustantivo de Trabajo (2020) define la empresa como toda unidad de explotación económica o las varias unidades dependientes económicamente de una misma persona natural o jurídica, que correspondan a actividades similares, conexas o complementarias y que tengan trabajadores a su servicio. La parte final del mencionado artículo señala que, en el caso de las personas jurídicas existirá unidad de empresa entre la principal y las filiales o subsidiarias en que aquella predomine económicamente, cuando todas cumplan actividades similares, conexas o complementarias.

Como se señaló de manera antecedente, la Constitución Política de Colombia (2020) indica que las empresas como base del desarrollo nacional tienen una función social que les genera también obligaciones dado que las actividades que ellas realizan tienen significativos impactos en los aspectos económicos, sociales y ambientales entre otros. En este orden de ideas, la empresa como base del desarrollo, fuente generadora de empleo y de bienestar, además de estar caracterizada por el interés económico o el ánimo de lucro para sus inversionistas, tiene una función social que implica obligaciones. La Corte Constitucional Colombiana, máximo organismo de cierre, ha sido reiterativa en la definición, naturaleza, límites y fundamentos del derecho a la libre competencia económica, así como sobre las prerrogativas y obligaciones que genera. En síntesis, la Corte ha interpretado que dicho derecho presenta las siguientes características:

- Se trata de un derecho individual que es de todos y que supone responsabilidades, conforme con lo dispuesto por el artículo 333 de la Constitución Política (2020).

- Simultáneamente es un derecho o interés colectivo que tiene por objeto defender los derechos o intereses de los consumidores de bienes y usuarios de servicios, conforme con lo dispuesto por el artículo 88 de la Constitución Política (2020). Es un derecho que no tiene carácter de fundamental y que por lo tanto no puede ser protegido por la vía de la acción de tutela.

En este sentido, el concepto sobre interés colectivo se debe aplicar de manera similar en las empresas privadas y en las empresas que tengan alguna participación estatal por cuanto su naturaleza jurídica es irrelevante dentro del compromiso social adquirido. La responsabilidad lleva impresa la característica que se deriva de un marco de condiciones legalmente establecidas, que le imprimen la denominación de empresa y, cuyo propósito es asumir el reto por parte de quienes tienen el carácter de actor empresarial como lo es además, de desarrollar una actividad con ánimo de lucro: asumir una función social.

Tal y como lo plantea Fernández (2005), en materia de responsabilidad:

tradicionalmente se pueden diferenciar dos tipos: uno relacionado con la propia esencia de la empresa, como pagar salarios, dar beneficios, relaciones con proveedores 
y clientes, etcétera, y otro relativo al cumplimiento de aquellas normas que la afectan, como impuestos, Seguridad Social, etcétera. Tienen, en consecuencia, una obligación legal, incurriendo en responsabilidad en caso de incumplimiento. Para aquellos supuestos en que no haya nada regulado y las empresas voluntariamente realicen contribuciones o esfuerzos en bien de terceros, habría que calificarlas de responsables, aportando algo a la sociedad, siendo, en consecuencia, empresas socialmente responsables.

El ejercicio de la actividad empresarial es un derecho que no excluye la intervención del Estado a quien le compete la dirección general de la economía, de acuerdo con lo normado por el artículo 334 de la Constitución Política (2020). Asimismo, el estado actuará a través de sus órganos o autoridades cuando lo requiera para cumplir sus funciones. La empresa es catalogada como una garantía constitucional de carácter relacional tal y como se refiere en la sentencia de la Corte Constitucional "cuya efectiva garantía depende del equilibrio entre las acciones individuales de las empresas e individuos participantes en el mercado" (Sala Plena, C-228, 2010). Por tal motivo, también es claro que

la satisfacción de la misma depende del ejercicio de funciones de inspección, vigilancia y control de las actuaciones de los agentes que concurren al mercado, con el objeto de evitar que incurran en comportamientos abusivos que afecten la competencia o, una vez acaecidos estos comportamientos, imponer las sanciones que prevea la ley. Este aspecto ha sido reiterado por nuestros jueces en diferentes oportunidades (Sala Plena, C-228, 2010).

De igual forma, es innegable que frente a los diferentes problemas sociales que vive el país, la responsabilidad social empresarial debe contribuir a la consolidación de un verdadero proceso de paz por cuanto con sus acciones estará generando oportunidades para que muchas personas puedan mejorar su calidad de vida al tiempo que esto también contribuye a aumentar los niveles de productividad de la organización a través del realce de su imagen corporativa; por ejemplo, por cuanto los aspectos sociales y económicos no son excluyentes entre sí, sino que por el contrario, son convictivos y contribuyen a generar desarrollo sostenible en los ámbitos sociales económicos y ambientales que deben caracterizar a una organización.

Es una realidad que la inestabilidad social, política, jurídica y económica vivida por muchos países es causada por las inequidades $\mathrm{y}$ desigualdades sociales que deben ser replanteadas. El auge del desarrollo económico, tecnológico y la informática, al igual que la dinámica de apertura en que está inmerso el país y el mundo, generan oportunidades para retomar paradigmas equivocados, como las prácticas excluyentes e individualistas, por cuanto el momento histórico constituye una posibilidad para que las empresas, trabajadores, comunidades y entidades del Estado aúnen esfuerzos por el bienestar común y la prevalencia del interés general sobre el particular. Esto posibilitará un verdadero aporte a la solución de tales problemas sociales y permitirá también una verdadera sostenibilidad económica, social y ambiental del país y de las organizaciones, a partir de la coordinación económica y el equilibrio social que debe caracterizar a una sociedad civilizada e incluyente.

En relación con lo anterior, la Sentencia C 042 de 2006 señala:

Pero es claro, tal y como lo ha puesto de presente nuestra Corte Constitucional que: "asimismo, corresponde al Estado estimular el desarrollo empresarial e impedir que se obstruya o restrinja la libertad económica. De la ley surgen, en consecuencia, tanto restricciones como estímulos a la libertad de empresa (Corte Constitucional, Sala Plena) ${ }^{1}$.

Por otra parte, la jurisprudencia constitucional también ha sostenido que: "el instrumento por excelencia que permite a las autoridades lograr la efectividad de la función social de la empresa, es la actividad estatal de intervención en la economía" (Constitución Política de Colombia, 2020, art. 334). Con dicha intervención, como lo ha sostenido una decisión judicial,

se pretende conciliar los intereses privados presentes en la actividad empresarial de los particulares, con el interés general que

1. Esto mismo fue señalado por la Sentencia C - 254 de 1996. 
está involucrado en dicha actividad en ciertos casos, como en el de la prestación de los servicios públicos que se vincula la satisfacción de necesidades básicas de los ciudadanos (Corte Constitucional, Sala Plena, C-616, 2001).

De lo señalado, podemos deducir que la responsabilidad de la empresa debe ser una constante que tiene fundamento en normas legales que, como tales, son vinculantes, pero que no siempre son tan conocidas, aún a pesar de que en Colombia existe la presunción de derecho de que la ley es conocida por todos y no admite prueba en contrario. Lo cierto es que en nuestra realidad no siempre la ley es conocida y aplicada como debería ser y, en materia de responsabilidad social pareciera que es igual por cuanto siempre se concibe como algo voluntario, olvidando que la Constitución Política le ha ordenado a la empresa asumir una función social que implica obligaciones por cuanto si bien le permite explotar una actividad con ánimo de lucro, lo cierto es que también se le imponen compromisos a la empresa hacia los aspectos sociales y ambientales, entre otros.

Para comprender un poco más esta responsabilidad, por un momento si se piensa en que a la empresa tan solo se le permitiera lucrarse de la explotación de una actividad económica sin alguna obligación o compromiso. Seguramente este concepto no encajaría dentro del modelo económico capitalista social, sino que por el contrario se saldría de él e implicaría un abuso de derecho por cuanto partiríamos tan solo del ejercicio de un derecho y no de la correlativa obligación de ejercerlo dentro de la órbita del interés general. Esta situación generaría bastante caos e inequidad por cuanto la empresa tan solo se dedicaría a buscar su propio beneficio a ultranza de los derechos de los demás lo que implicaría un pésimo mensaje para la sociedad.

Por el contrario, con respecto al tema de la responsabilidad legal y social se puede diferenciar que en las organizaciones tradicionalmente se perciben dos tipos de responsabilidades: la primera, se relaciona con el propio giro de sus actividades o el desarrollo de su objeto social como pagar salarios, otorgar los recargos por trabajo extra, dominical o festivo, reconocer y pagar vacaciones, pagar auxilio de cesantía $\mathrm{y}$ sus intereses, primas de servicios, pagos a proveedores y clientes, etcétera. Además, implica el cumplimiento de aquellas normas que la afectan, como impuestos fiscales y parafiscales con destino a la Dirección de Impuestos y Aduanas Nacionales (DIAN), al Servicio Nacional de Aprendizaje (SENA), al Instituto Colombiano de Bienestar Familiar (ICBF), a las Cajas de Compensación Familiar; y efectuar los aportes a la seguridad social integral en pensiones, salud y riesgos laborales de sus empleados. La segunda forma de responsabilidad de la organización, tiene que ver con la incidencia de su dinámica económica en la contribución al mejoramiento de las condiciones y calidad de vida de la sociedad a través de programas o acciones que involucren a otros actores sociales como las comunidades del entorno en donde funcionan sus centros de trabajo. Lo anterior también implicaría el cumplimiento de estándares, protocolos y políticas que por ejemplo coadyuven a preservar los recursos naturales y el desarrollo sostenible a través de la producción limpia de sus productos o en la prestación de sus servicios, así como en la inversión social en jornadas culturales, de recreación o fomento del deporte para la población circunvecina o que las organizaciones participen en la construcción de vías de acceso o en la contribución al sostenimiento de establecimientos educativos para los niños pertenecientes a familias de menores ingresos.

En este sentido, el concepto de responsabilidad debe abarcar los aspectos legales y sociales. En este orden de ideas, en el país existen nomas legales que establecen que no se puede contaminar las cuencas hídricas con cianuro, mercurio, u otra sustancia tóxica o deshecho de su proceso. Cuando la organización se limita a cumplir estrictamente lo regulado está cumpliendo con su responsabilidad legal y no sería objeto de sanciones. Ahora bien, si la empresa en desarrollo de su actividad económica no solo se abstiene de contaminar las fuentes hídricas, sino que además de forma voluntaria y consciente siembra árboles y mantiene un sistema de extractores y de rotación del aire puede decirse que está actuando de forma solidaria con el medio ambiente y por lo tanto se habla de responsabilidad social. Es por ello que algunos tratadistas se refieren a que con la responsabilidad social empresarial vamos más allá del simple cumplimiento del deber legal.

En razón a lo anterior, es acertada la reflexión de Pimentel (2004) cuando sostiene que: 
para hablar de responsabilidad social, las empresas primero deben cumplir con sus obligaciones señaladas por la ley, para luego ocuparse en el valor agregado que caracteriza la responsabilidad social y que debe proyectarse como una filosofía corporativa y no simplemente como estrategia de mercadeo o acción cosmética.

Esta reflexión trae como corolario que la empresa no se debe limitar tan solo a cumplir con lo establecido por la ley, sino que en desarrollo de su función social su actividad económica debe trascender más allá y generar como valor agregado la contribución al mejoramiento de la calidad de vida de todos. Es por ello que la Carta Política en el titulo referente a los Derechos Colectivos y del Ambiente, señala que:

la ley regulará el control de calidad de bienes y servicios ofrecidos y prestados a la comunidad, así como la información que debe suministrarse al público en su comercialización. Serán responsables, de acuerdo con la ley, quienes en la producción y en la comercialización de bienes y servicios, atenten contra la salud, la seguridad y el adecuado aprovisionamiento a consumidores y usuarios. El Estado garantizará la participación de las organizaciones de consumidores y usuarios en el estudio de las disposiciones que les conciernen. Para gozar de este derecho las organizaciones deben ser representativas y observar procedimientos democráticos internos (2020, art. 78).

Esta responsabilidad legal a la que alude la citada norma lleva inmersa una responsabilidad social y es la que tiene que ver con la calidad del aire, en general con el medio ambiente y el bienestar físico, mental, social y aún espiritual que ello genera.

En este sentido, así como las empresas en el desarrollo de su actividad productiva deben evitar la contaminación del ambiente, también cada ciudadano desde su espacio como actor corresponsable debe evitarla y hacer aportes para la preservación de un medio ambiente sano, tal y como lo plantea la Constitución Política que a la letra dice: "todas las personas tienen derecho a gozar de un ambiente sano" (2020, art. 79). En este aspecto, cobra todo sentido la afirmación de que es deber del Estado proteger la diversidad e integridad del ambiente, conservar las áreas de especial importancia ecológica y fomentar la educación para el logro de estos fines.

Esta misma reflexión es pertinente en las otras órbitas en que se proyecta la responsabilidad social y que tienen que ver con los derechos de las personas en una sociedad, por cuanto cada uno debe contribuir para evitar la exclusión, la discriminación y en general, a no vulnerar los derechos del otro en los diferentes campos lo que a su vez contribuirá al fomento de la convivencia pacífica y por ende a la construcción de paz. $\mathrm{Al}$ respecto es pertinente recordar una frase célebre pronunciada por el indígena presidente de los Estados Unidos Mexicanos Benito Juárez, cuando se restauró la República en México, en el año 1867: "el respeto al derecho ajeno es la paz" (Fonseca, 2011).

Acorde con lo anterior, en materia de responsabilidad legal y social, el artículo 95 de la Constitución Política (2020) señala que:

la calidad de colombiano enaltece a todos los miembros de la comunidad nacional. Todos están en el deber de engrandecerla y dignificarla. El ejercicio de los derechos y libertades reconocidos en esta Constitución implica responsabilidades.

Toda persona está obligada a cumplir la Constitución y las leyes.

Son deberes de la persona y del ciudadano:

1. Respetar los derechos ajenos y no abusar de los propios; 2 . Obrar conforme al principio de solidaridad social, respondiendo con acciones humanitarias ante situaciones que pongan en peligro la vida o la salud de las personas; 3. Respetar y apoyar a las autoridades democráticas legítimamente constituidas para mantener la independencia y la integridad nacionales. 4. Defender y difundir los derechos humanos como fundamento de la convivencia pacífica; 5. Participar en la vida política, cívica y comunitaria del país; 6 . Propender al logro y mantenimiento de la paz; 7. Colaborar para el buen funcionamiento de la administración de la justicia; 8 . Proteger los recursos culturales y naturales del país y velar por la conservación de un ambiente sano; 9. Contribuir al financiamiento de los gastos e 
inversiones del Estado dentro de conceptos de justicia y equidad.

De otro lado, la responsabilidad social implicará, de parte de cada uno de los individuos, el ejercicio de acciones que se deriven de estas obligaciones legales y que se articulen con otros propósitos que impliquen una proyección más amplia de las mismas, por cuanto el reto social va más allá del cumplimiento de la ley.

Dado lo anterior, dentro de un Estado Social de Derecho también es oportuno difundir, a todo nivel, el contenido de las diferentes normas legales que regulan los derechos y obligaciones de otros actores sociales corresponsables socialmente como, por ejemplo, la ley estatutaria 1757 (2015), por la cual se dictan disposiciones en materia de promoción y protección del derecho a la participación democrática. En particular, el título VIII sobre alianzas para la prosperidad señala que:

En los municipios donde se desarrollen proyectos de gran impacto social y ambiental producto de actividades de explotación minero-energética, se podrán crear a nivel municipal alianzas para la prosperidad como instancias de diálogo entre la ciudadanía, especialmente las comunidades de áreas de influencia, la administración municipal, el Gobierno Nacional y las empresas que desarrollen proyectos con el fin de concertar $\mathrm{y}$ hacer seguimiento al manejo de dichos impactos.

Asimismo, dentro de la citada norma, también se regula la figura del dialogo social, concebido como un mecanismo democrático para la participación ciudadana $\mathrm{y}$ el fortalecimiento de las organizaciones de la sociedad civil, con el objetivo de promover la interacción, comunicación, consulta y seguimiento de políticas públicas a nivel nacional y territorial, en donde seguramente se incluirán aspectos referentes a los procesos productivos y la generación de empleo y bienestar para las comunidades. En la misma línea, en el artículo 104 sobre deberes de las administraciones nacionales, departamentales, municipales y distritales en la promoción de instancias de participación ciudadana formales e informales creadas y promovidas por la ciudadanía o el Estado, señala que: "el Estado en todos sus niveles de organización territorial nacional, bajo el liderazgo de las administraciones, tiene la obligación de: a). Promover, proteger, implementar y acompañar instancias de participación; b). Garantizar la participación ciudadana en los temas de planeación del desarrollo, de políticas sociales, de convivencia ciudadana, reconciliación, y de inclusión de poblaciones tradicionalmente excluidas (Ley 1757, 2015).

Es claro que este tipo de mecanismos de participación y su dinamización contribuyen a que los individuos y las comunidades se empoderen de su condición como sujetos de derecho y de correlativas obligaciones como actores sociales corresponsables. En este aspecto se considera que la responsabilidad social debe aplicar en doble sentido. De una parte las empresas deben concientizarse de su responsabilidad social y para el efecto diseñar y desarrollar estrategias para hacerla real, masificar la información en torno ellas y convertirlas en hechos concretos que contribuyan a la prosperidad general y a una verdadera inclusión social. De otra parte, los individuos y las comunidades deben ser informados a través de diferentes estrategias de comunicación, en torno a las prácticas de responsabilidad social empresarial y también deben asumir la obligación de difundirlas y exigir que se lleven a cabo en la realidad a través de mecanismos de control social como los ya señalados.

Es es importante recordar que los objetivos del desarrollo sostenible adoptados por la Asamblea General de las Naciones Unidas y concebidos como un llamado universal para poner fin a la pobreza, proteger el planeta $\mathrm{y}$, garantizar que todas las personas gocen de paz y prosperidad para 2030, guardan relación directa con el tema abordado. Los referidos objetivos incluyen: poner fin a la pobreza en todas sus formas en todo el mundo, garantizar una vida sana y promover el bienestar para todos en todas las edades, lograr la igualdad entre los géneros, garantizar la disponibilidad de agua y su ordenación sostenible y el saneamiento para todos; promover el crecimiento económico sostenido, inclusivo y sostenible, el empleo pleno y productivo y el trabajo decente para todos; lograr que las ciudades y los asentamientos humanos sean inclusivos, seguros, resilientes y sostenibles; y promover sociedades pacíficas e inclusivas para el desarrollo sostenible (2019). 
Como se observa, los citados objetivos multilaterales buscan contribuir con el mejoramiento de la calidad de vida de las personas y el desarrollo de los países inspirado en la coordinación económica y el equilibrio social. De manera similar, la Organización para la Cooperación y el Desarrollo Económico OCDE (2019) al referirse a los indicadores sociales, señaló que han mejorado, pero Colombia sigue siendo un país muy desigual:

las desigualdades afectan especialmente a las minorías étnicas y a las personas desplazadas por el conflicto, que se concentran de manera desproporcionada en las zonas rurales. La desigualdad también es una cuestión de género, ya que el empleo femenino es bajo y las diferencias salariales han ido en aumento. El creciente flujo de inmigración procedente de Venezuela afecta principalmente a las regiones noroccidentales del país, lo que se suma a las disparidades regionales (p. 49).

Es por ello que el Estado y dentro de él las comunidades y los individuos deben contribuir al desarrollo social con su trabajo permanente a partir de una injerencia más informada empoderada y decidida en el uso adecuado de los mecanismos de participación tal y como lo regula la pluricitada Ley Estatutaria 1757 (2015), por la cual se dictan disposiciones en materia de promoción y protección del derecho a la participación democrática. En ella, además se refiere que

en los municipios donde se desarrollen proyectos de gran impacto social y ambiental producto de actividades de explotación minero-energética, se podrán crear a nivel municipal alianzas para la prosperidad como instancias de diálogo entre la ciudadanía, especialmente las comunidades de áreas de influencia, la administración municipal, el Gobierno Nacional y las empresas que desarrollen proyectos con el fin de concertar $\mathrm{y}$ hacer seguimiento al manejo de dichos impactos (Art.105).

Este aspecto es reiterado por el artículo 111 de la citada norma, sobre el diálogo social como mecanismo democrático para la participación ciudadana y el fortalecimiento de las organizaciones de la sociedad civil, con el objetivo de promover la interacción comunicación consulta y el seguimiento de políticas públicas a nivel nacional y territorial. En este mismo sentido, la Ley 850 (2003), garantiza el ejercicio del control social que permite a los ciudadanos o a las diferentes organizaciones comunitarias ejercer vigilancia sobre la gestión pública respecto a las autoridades administrativas, políticas, judiciales, electorales, legislativas y órganos de control, así como de las entidades públicas o privadas, organizaciones no gubernamentales de carácter nacional o internacional que operen en el país encargadas de la ejecución de un programa, proyecto, contrato o de la prestación de un servicio público.

Como se observa, a partir de los anteriores referentes internacionales $\mathrm{y}$ nacionales las acciones y estrategias de todos los actores sociales se deben alinear para el logro de objetivos comunes a partir de la corresponsabilidad y la cohesión sociales con el fin de desarrollar acciones que contribuyan a la defensa de los derechos individuales y colectivos de todas las personas. Dentro de este propósito las organizaciones productivas asumen el gran reto de aportar con su trabajo, esfuerzo e innovación, al fomento de la protección holística de los entornos comunitarios con un alto sentido de sensibilidad y responsabilidad social.

Por todo lo anterior, se puede concluir que la responsabilidad legal y social de las organizaciones son complementarias más no excluyentes. La una no asume la otra, sino que cada una tiene una vigencia independiente, pero convergen a partir de la diversidad para la construcción de paz. Un ejemplo de la deseada y necesaria articulación entre la responsabilidad legal y social la encontramos en la Ley 1503 (2011), modificada por la Ley 1811 (2016), la cual tiene por objeto definir lineamientos generales en educación, responsabilidad social empresarial (negrillas nuestras) y acciones estatales y comunitarias para promover en las personas la formación de hábitos, comportamientos y conductas seguros en la vía y en consecuencia la formación de criterios autónomos, solidarios y prudentes para la toma de decisiones en situaciones de desplazamiento o de uso de la vía pública. En este sentido, la ley señala que son actores de la vía todas las personas que asumen un rol determinado para hacer uso de las vías con la finalidad de desplazarse entre un lugar y otro, por lo tanto se consideran actores de tránsito y de la vía los peatones, los transeúntes, 
los pasajeros y conductores de vehículos automotores y no automotores, los motociclistas, los ciclistas, los acompañantes, los pasajeros, entre otros. En este aspecto, la empresa frente a la comunidad asume una gran responsabilidad social por cuanto, a través de sus actores viales, debe contribuir a la disminución de accidentes en la vía pública, por medio del diseño de un plan estratégico de seguridad vial cuyo propósito es salvar vidas.

Como corolario de lo anterior es claro que, como actores sociales todas las personas debemos participar en la búsqueda de mejores oportunidades para el desarrollo humano independientemente de cualquier factor subjetivo y enfocados en las personas como sujetos de derecho. En este orden de ideas resulta necesario que los individuos y las comunidades conozcan sus derechos la forma de hacerlos efectivos y que también tengan claros los mecanismos con los que cuentan para lograr su eficacia y restablecimiento frente a una eventual amenaza o vulneración efectiva. Así pues los individuos y comunidades cuentan con una rica y variada normatividad legal que le apuesta a la inclusión y a la participación social y, que en la mayoría de los casos no es conocida, lo que amerita una mayor difusión temática en el contexto social a través de diferentes estrategias, dada la gran diversidad.

De otro lado, más que normas legales de emprendimiento o que intenten resolver las problemáticas sociales, como ha sido la tradición en Colombia, se deben impulsar acciones que repercutan en un cambio cultural a partir del beneficio colectivo y el impacto en las personas. Esto por cuanto en el "statu quo", que como locución en latín significa estado del momento actual, los problemas sociales generados por la inequidad social se ven reflejados en hechos de violencia en los que tradicionalmente ha vivido el país. Por tal motivo, es de suma urgencia social la generación de espacios de inclusión y de equidad que tengan como referente la equitativa distribución de la riqueza y las oportunidades para todos, lo que contribuye a la construcción de escenarios de paz a partir de un desarrollo humano integral. Este propósito, como se señaló de manera antecedente, se ve reflejado en instrumentos tales como las metas del desarrollo Sostenible de la Organización de Naciones Unidas.
No obstante, en la búsqueda del propósito sobre la consolidación de la tan anhelada paz en Colombia las oportunidades dependen del grado de compromiso de cada actor social en la búsqueda del beneficio colectivo y el reconocimiento del otro con sus diferencias. $\mathrm{Al}$ mismo tiempo, deberán respetarse los derechos de los demás, así no pertenezcan a la misma especie humana, como los derechos de los animales como seres sintientes, los ríos y el aire como sujetos de derecho. Lo anterior, por cuanto junto con el derecho a la vida que es el derecho fundamental por excelencia, la calidad de vida también resulta de vital trascendencia debido a que al ser humano no le es suficiente existir, sino que además debe contar con las condiciones necesarias que contribuyan al mejoramiento de su vida y de su calidad de vida que como se señaló de manera antecedente se traduzcan en un estado de bienestar físico, mental, social y espiritual, tal y como lo han sostenido, entre otros actores, la Organización Mundial de la Salud, la Organización Internacional del trabajo y la ley estatutaria de salud en Colombia. Consideremos que en este aspecto, el país también ha avanzado bastante, sobre todo a nivel de decisiones judiciales, como por ejemplo, las sentencias C-041 (2017), T-622 (2016), C-133 (2019) y C-045 (2019), que entre otras, visualizan a los animales que, aunque no son sujetos de derecho, son objetos de protección constitucional, y a los ríos los concibe como sujetos de derecho y por lo tanto, sujetos de especial protección, por cuanto a través de ellos también se garantiza una calidad de vida para las personas dada la relación simbiótica que caracteriza al planeta. Al respecto, la referida sentencia C-045 (2019), agrega además que: "las empresas tienen una función social y ecológica, lo cual implica el cumplimiento de obligaciones, como la protección del bienestar animal y la protección de los recursos naturales" (Corte Constitucional, Sala Plena, 2019, art. 333).

Por lo anterior, en la búsqueda de una anhelada convivencia pacífica no basta tan solo estar en paz con los sujetos de nuestra especie, sino también con todo el planeta y sus recursos. Este aspecto también debería ser tenido en cuenta en el futuro, en el momento de abordar investigaciones alrededor del tema de la paz, debido a que los recursos naturales son conexos con ella sobre todo a partir del concepto de desarrollo sostenible y/o sustentable que se pregona en el planeta. Al respecto, es oportuno recordar que muchas de 
las acciones bélicas de grupos al margen de la ley en el país, han tenido como objetivo los recursos naturales o, indirectamente éstos han sido involucrados dentro de las acciones delictivas generadas especialmente como producto de la inequidad social y la corrupción rampantes que lo caracterizan. Al respecto, es necesario recordar que estas conductas están tipificadas como delitos, tal y como lo señala el Código Básico Penal y de Procedimiento Penal (2020), en el Titulo XI De Los Delitos Contra Los Recursos Naturales y el Medio Ambiente. Lo anterior sin perjuicio de la aplicación de lo previsto por la Ley 1333 (2009), por la cual se establece el procedimiento Sancionatorio Ambiental por las infracciones en esta materia, en concordancia con el Decreto 1076 (2015), por medio del cual se expide el Decreto Único Reglamentario del Sector Ambiente y Desarrollo Sostenible.

\section{Al respecto, González (2018) señala que}

en la medida que la paz implica más que un estado de tranquilidad, bienestar y armonía que se alcanza o se posee, la actitud política de los miembros de una sociedad, en tanto les permite actuar y opinar frente a los fenómenos sociales, se convierte en el eje fundamental para transitar en la construcción de paz, toda vez que esta se materializa a través de la relación con el otro (p. 9).

En este mismo sentido, como lo señalan algunos estudios,

podría decirse que la responsabilidad social empresarial se refiere a un conjunto de compromisos $u$ obligaciones que el empresario o el hombre de negocios han decidido asumir yendo más allá de su esquema tradicional de utilidades o pérdidas o de lo que le es normal y legalmente exigible (Procolombia, 2016).

Este aspecto, realza aún más la función social de la empresa y de la propiedad en su contribución a la construcción de tejido social.

Es por ello que en la construcción de un proceso de paz se ha de insistir en que este propósito debe corresponder al diseño, implementación y monitoreo de políticas de Estado que trasciendan en su implementación más allá de los Gobiernos de turno y, que se proyecten en el tiempo con el fin de consolidar una cultura alrededor de la paz. Es claro que este aspecto debe interiorizarse por cada actor social y no simplemente afirmarse como parte de la retórica. En la implementación y ejecución de políticas públicas no se han obtenido los resultados esperados en la construcción de la tan anhelada paz. Al respecto, algunos autores han señalado que:

ante la implementación de un acuerdo de paz como el nuestro, los desafíos y retos son innumerables: contar con la voluntad política para legislar, el presupuesto y la capacidad instalada de la administración y los egos de los dirigentes y sus intereses ante la paz es muy difícil. Una educación para la cultura de paz puede llegar a ser una vía de garantía de no repetición, un país en donde culturalmente se respete la vida, se trabaje por el bien común, se enseñe el derecho y el deber en un nivel de corresponsabilidad entre las comunidades y con el Estado, será un lugar en donde las mismas personas garantizaran la no repetición de la violación de derechos humanos (González, 2018, p. 18).

\section{CONCLUSIONES}

El trabajo se origina en el artículo 25 de la Carta Política de los colombianos como un derecho y una obligación social que goza, en todas sus modalidades, de la especial protección del Estado. Para que se desarrolle en condiciones dignas y justas, debe estar fundamentado en la concepción del derecho inviolable a la vida y a la calidad de vida.

De acuerdo con el artículo 333 de la Constitución Política la libre competencia económica es un derecho de todos y supone responsabilidades. La empresa, como base del desarrollo, tiene una función social que implica obligaciones. Así pues, las organizaciones productivas deben llevar a cabo acciones que se traduzcan en aportes que contribuyan al desarrollo económico y social del país y a la solución de problemas sociales.

Dentro de la dinámica de apertura, a que alude el artículo 227 de la Carta Política, la celebración de tratados de libre comercio y acuerdos comerciales son instrumentos que permiten el desarrollo económico y social de los países. Es por ello que dentro de las negociaciones internacionales se incluyen cada vez más las 
cláusulas sociales en las cuales se regulan los temas relacionados con la responsabilidad social y legal empresarial. Este aspecto, al igual que su seguimiento, debería ser un requisito ineludible para la firma de dichos acuerdos y tratados.

El diálogo social es un mecanismo democrático para la participación ciudadana y el fortalecimiento de las organizaciones de la sociedad civil con el objetivo de promover la interacción, comunicación, consulta y seguimiento de políticas públicas a nivel nacional y territorial.

En los municipios donde se desarrollen proyectos de gran impacto social y ambiental producto de actividades de explotación mineroenergética y, en general cualquier otra actividad económica, se podrán crear a nivel municipal alianzas para la prosperidad como instancias de diálogo entre la ciudadanía (especialmente las comunidades de áreas de influencia), la administración municipal, el gobierno local, regional y aún el nacional, y las empresas que desarrollen tales proyectos con el fin de concertar y hacer seguimiento de los impactos económicos, sociales y ambientales.

El Estado en todos sus niveles de organización nacional y territorial, bajo el liderazgo de las administraciones, tiene la obligación de garantizar la participación ciudadana en los temas de planeación del desarrollo, de políticas sociales, convivencia ciudadana, reconciliación e inclusión de poblaciones tradicionalmente excluidas, tal como lo establece la ley.

El control social debe contribuir a la garantía $\mathrm{y}$ al restablecimiento de los derechos de todas las personas.
La única forma de contrarrestar la pobreza es la generación de riqueza. El reto de erradicar la pobreza y apostarle a la generación de riqueza son un asunto de todos los actores sociales y dentro de ellos las empresas, las cuales no podrán crecer ni desarrollarse en un país que no asuma a través de todos una verdadera responsabilidad social y legal.

Es necesario reiterar que en las organizaciones $\mathrm{y}$ en los diferentes entornos sociales los empleadores, trabajadores, comunidades e individuos, a igual que los demás actores sociales son responsables, por cuanto cada uno desde su rol o condición humana debe contribuir a la construcción de la paz mejorar la calidad de vida y el progreso del país.

Es conveniente que todos los sistemas de gestión de las organizaciones, tales como el medioambiental, de calidad, el laboral, de responsabilidad social, de gestión y atención de desastres, de seguridad y salud en el trabajo, entre otros, estén articulados con el objeto de aunar acciones para proteger a la población en general a través de estrategias que generen entornos laborales y comunitarios saludables e incluyentes a partir de la diversidad (Decreto 1072, 2015)

En un Estado Social de Derecho, como Colombia, es pertinente que todos los actores sociales conozcan sus derechos y deberes legales $\mathrm{y}$ sociales, al igual que las consecuencias que puede generar su inobservancia, especialmente en cuanto a la imposición de sanciones pecuniarias, sociales, restrictivas de la libertad, entre otras, como forma de prevenir la ocurrencia de hechos que pueden generar desequilibrios sociales, violencia y exclusiones.

\section{BIBLIOGRAFÍA}

- Cámara de Comercio de Bogotá, Fundación Ideas para la Paz, Instituto Catalán Internacional para la Paz. (22 de abril de 2015). Perspectivas y aportes empresariales para la construcción de paz. Centro de Información Empresarial (CIEB): Disponible en https://bibliotecadigital.ccb.org.co/ handle/11520/8482
- Código Básico Sustantivo y Procesal del Trabajo [Código]. (2020). Bogotá: Legis.

- Código de Comercio [Código]. (2020). Bogotá: Legis.

- Código Básico Penal y de Procedimiento Penal. [Código]. (2020). Bogotá: Legis.

- Constitución Política de Colombia [Const.] (2020). Bogotá: Legis 
- Corte Constitucional, Sala Plena. (6 de junio de 1996). Sentencia C-254. [MP Eduardo Cifuentes Muñoz]

- Corte Constitucional, Sala Plena. (13 de junio de 2001). Sentencia C-616. [MP Rodrigo Escobar Gil]

- Corte Constitucional, Sala Plena. (1 de febrero de 2006) Sentencia C-042. [MP Clara Inés Vargas Hernández]

- Corte Constitucional, Sala Plena. (15 de marzo de 2006) Sentencia C-189. [MP Rodrigo Escobar Gil]

- Corte Constitucional, Sala Plena. (24 de marzo de 2010) Sentencia C-228. [MP Luis Ernesto Vargas Silva]

- Corte Constitucional, Sala Sexta de Revisión. (10 de noviembre de 2016) Sentencia T-622. [MP Jorge Iván Palacio Palacio]

- Corte Constitucional, Sala Plena. (1 de febrero de 2017) Sentencia C-041. [MP Jorge Iván Palacio Palacio, Gabriel Eduardo Mendoza Martelo]

- Corte Constitucional, Sala Plena. (6 de febrero de 2019) Sentencia C-045. [MP Antonio José Lizarazo Ocampo]

- Corte Constitucional, Sala Plena. (27 de marzo de 2019) Sentencia C-133. [MP José Fernando Reyes Cuartas, Antonio José Lizarazo Ocampo]

- Decreto por medio del cual se expide el Decreto Único Reglamentario del Sector Ambiente y Desarrollo Sostenible (1076/ mayo 26 de 2015). Diario Oficial: 49523. Ministerio de Ambiente y Desarrollo Sostenible.

- Decreto por medio del cual se expide el Decreto Único Reglamentario del Sector Trabajo (1072/26 de mayo de 2015). Diario Oficial: 49523. Ministerio del Trabajo.

- Fernández S., J. (21 de julio de 2005). Responsabilidadlegalysocialdelasempresas. CincoDías. Disponible en https://cincodias. elpais.com/cincodias/2005/07/21/ economia/1122058548_850215.html.
- Fonseca A., R. (2011). "El respeto al derecho ajeno es la paz". Benito Juárez. Expresidente de México. Biociencias, 9. Disponible en https://dialnet.unirioja.es/servlet/ articulo?codigo $=6588148$.

- González García, E. Y. (2018). Los derechos humanos como mecanismo de construcción y desarrollo de la cultura de paz y reconciliación en el Pos acuerdo en Colombia. Colombia.

- González Gaviria, M. A. (diciembre de 2018). “¿Cómo influye la actitud política del ciudadano en la construcción de la paz en Colombia?" Subjetividad y Sociedad (3), pp. 8-9. Disponible en http://www.uniminuto. edu/documents / 991974/15123613/ Anexo+4_Numero+3.pdf/61982c4e-51ce4b5b-a434-ee38e1a665d4.

- Ley a través de la cual se promueve la formación de hábitos, comportamientos y conductas seguros en la vía. (1503/29 de diciembre de 2011). Diario Oficial: 48298. Congreso de la República de Colombia.

- Ley estatutaria por la cual se dictan disposiciones en materia de promoción y protección del derecho a la participación democrática. (1757/6 de julio de 2015). Diario Oficial: 49565. Congreso de la República de Colombia.

- Ley por la cual se establece El Procedimiento Sancionatorio Ambiental y se Dictan Otras Disposiciones. (1333/21 de julio de 2009). Diario Oficial: 47.417. Congreso de la República de Colombia.

- Ley por la cual se otorgan incentivos para promover el uso de la bicicleta en el territorio nacional y se modifica el Código Nacional de Tránsito. (1811/21 de octubre de 2016). Diario Oficial: 50033. Congreso de la República de Colombia.

- Ley por medio de la cual se reglamentan las veedurías ciudadanas. $(850 / 19$ de noviembre de 2003). Diario Oficial: 45.376. Congreso de la República de Colombia. 
- Naciones Unidas. (2019). Objetivos de desarrollo sostenible. Disponible en https:// www.un.org/sustainabledevelopment/es/ objetivos-de-desarrollo-sostenible/.

- OCDE (2019). Estudios Económicos de la OCDE: Colombia 2019, OECD Publishing Paris. Disponible en https://doi. org/10.1787/805f2a79-es.

- Pimentel, M. (29 de diciembre de 2004). "Responsabilidad social corporativa y marketing social”. CincoDías. Disponible en https://cincodias. elpais.com/cincodias/2004/12/29/ economia/1104436545_850215.html.
- Procolombia. (2016). Guía legal para hacer negocios en Colombia. Disponible en https://www.inviertaencolombia.com.co/ Guia_Legal_2016.pdf.

- Unidad Policial para la Edificación de la Paz. (2017). Modelo de Construcción de Paz de la Policía Nacional. Disponible en https:// www.interpeace.org/latinoamerica/ wp-content/uploads/sites/7/2017/05/ Modelo-de-Construccion-de-Paz-PoliciaNacional-de-Colombia-compressed.pdf.

- Williams, R. (1981). Sociología de la cultura. Barcelona: Ediciones Paidos. 